\title{
INTERVENSI HIDDEN VEGETABLE TERHADAP PENERIMAAN SAYURAN PADA ANAK PRASEKOLAH DI TK PGRI 21 KARANGASEM KOTA SEMARANG
}

\author{
Liska Widiyastuti, Adriyan Pramono*) \\ Program Studi Ilmu Gizi Fakultas Kedokteran Universitas Diponegoro \\ Jl.Dr.Sutomo No.18, Semarang, Telp (024) 8453708, Email : gizifk@ undip.ac.id
}

\begin{abstract}
Background: The vegetables acceptance were low in preschool age children. Bitter taste in vegetables allegedly resulted in low vegetables acceptance. Hidden vegetable was method of adding vegetable puree into food. The aim of this study was determine the differences of vegetables acceptance in preschool children.

Methods: This was a praexperimental design with static group comparison. Subjects were 20 preschool children divided into 2 groups: control and experimental group consisted of 10 subjects for each group. Subjects were selected based on purposive sampling method. Dishes for control group were chicken meatballs and green cabbage stew, chicken nuggets and boiled carrot, potatoes cakes and boiled broccoli. Dishes for experimental group were green cabbage meatballs, chicken-carrots nuggets, and broccoli cakes. This study was conducted over 3 days. Chi-square and Fisher's exact test were performed for data analysis.

Results: Subjects in control group prefer green cabbage, carrot, and broccoli were 1 subject (10\%), 4 subjects (40\%), and 3 subjects (30\%). Subjects in experimental group prefer green cabbage, carrot, and broccoli were 9 subjects (90\%), 10 subjects (100\%), and 9 subjects (90\%). There were differences in acceptance of green cabbage $(p=0,000)$, carrot $(p=0,011)$, and broccoli $(0,020)$ in control and experimental group.

Conclusions: There were differences in acceptance of green cabbage, carrot, and broccoli between control and experimental group.

Keyword : vegetables acceptance, preschool children, hidden vegetable
\end{abstract}

\section{ABSTRAK}

Latar belakang: Penerimaan sayuran yang rendah terjadi pada anak usia prasekolah. Rasa pahit pada sayuran diduga berakibat pada rendahnya penerimaan sayuran. Hidden vegetable adalah metode penambahan puree (bubur) sayuran ke dalam makanan. Penelitian ini bertujuan untuk mengetahui adanya perbedaan penerimaan sayuran pada anak prasekolah.

Metode: Jenis penelitian adalah praexperimental design dengan rancangan static group comparison. Subjek sebanyak 20 anak dibagi menjadi 2 kelompok yaitu kelompok kontrol dan perlakuan dengan masing - masing kelompok terdiri dari 10 anak. Subjek diambil dengan menggunakan metode purposive sampling. Hidangan untuk kelompok kontrol berupa bakso ayam dan sawi hijau rebus, nugget ayam dan wortel rebus, serta perkedel kentang dan brokoli rebus. Hidangan untuk kelompok perlakuan berupa bakso sawi hijau, nugget ayam wortel, dan perkedel brokoli. Penelitian dilakukan selama 3 hari berturut - turut. Analisis data menggunakan uji Chi-Square dan Fisher's Exact Test.

Hasil: Jumlah subjek pada kelompok kontrol yang menyukai sawi hijau sebanyak 1 orang (10\%), wortel 4 orang (40\%), dan brokoli 3 orang (30\%); sedangkan pada kelompok perlakuan jumlah subjek yang menyukai sawi hijau sebanyak 9 orang (90\%), wortel 10 orang (100\%), dan brokoli 9 orang (90\%). Ada perbedaan penerimaan sawi hijau $(p=0,000)$, wortel $(0,011)$, dan brokoli $(0,020)$ pada kelompok kontrol dan perlakuan.

Simpulan: Terdapat perbedaan penerimaan sawi hijau, wortel, dan brokoli antara kelompok kontrol dan perlakuan. Kata Kunci : Penerimaan sayuran, anak prasekolah, hidden vegetable

\section{PENDAHULUAN}

Konsumsi sayuran dan buah yang rendah terjadi pada semua kelompok usia terutama pada anak usia prasekolah. Kebiasaan makan pada anak prasekolah ditentukan oleh preferensi atau pemilihan makanan. ${ }^{1}$ Anak - anak pada kelompok usia ini hanya mengkonsumsi makanan yang mereka sukai atau yang tersedia di lingkungan mereka, sedangkan menolak untuk makan makanan yang mereka tidak suka atau makanan baru. ${ }^{1}$ Preferensi makanan, sikap, dan perilaku makan seseorang akan terbentuk terutama dalam enam tahun pertama kehidupan. ${ }^{2}$ Menerapkan kebiasaan makan pada anak sejak dini dengan menyediakan makanan yang sehat seperti sayuran dan buah akan berpengaruh pada kebiasaan makan pada usia dewasa. ${ }^{1}$

Sayuran dan buah merupakan komponen penting dalam makanan yang berperan dalam pencegahan penyakit. ${ }^{3-5}$ Konsumsi sayuran dan buah yang rendah berkaitan erat dengan peningkatan risiko penyakit kronis seperti obesitas, diabetes, kanker, jantung koroner, dan stroke. ${ }^{6-9}$ Berdasarkan temuan studi tahun 2000 menunjukkan 
bahwa 4,4\% dari keseluruhan beban penyakit di Eropa disebabkan karena rendahnya konsumsi sayuran dan buah. ${ }^{10}$

Rekomendasi kecukupan konsumsi sayuran untuk anak usia 2 - 5 tahun berdasarkan United States Departement of Agriculture (USDA) adalah sebanyak $150 \mathrm{~g} /$ hari atau sebanyak $11 / 2-2$ porsi sayuran sehari. ${ }^{11}$ Fenomena kurangnya konsumsi sayuran dan buah pada anak terjadi di seluruh dunia seperti Amerika, Eropa, Australia, dan Indonesia. ${ }^{12}$ Berbagai penelitian secara konsisten menunjukkan bahwa konsumsi sayuran pada anak - anak jauh dibawah jumlah yang dianjurkan. ${ }^{13-16}$ Berdasarkan studi tentang konsumsi sayuran dan buah yang dilakukan pada anak usia $2-5$ tahun menunjukkan bahwa anak prasekolah mengkonsumsi $25 \%$ sayuran dan $80 \%$ buah dari jumlah yang direkomendasikan. ${ }^{17}$ Hasil dari Continuing Survey of Food Intakes by Individuals (CFSII) menemukan $48 \%$ anak laki - laki dan $46 \%$ anak perempuan usia $2-5$ tahun mengkonsumsi buah sesuai rekomendasi minimum yaitu sebanyak 2 porsi sehari sedangkan untuk konsumsi sayuran ditemukan bahwa $24 \%$ laki - laki dan perempuan usia 2 - 5 tahun mengkonsumsi sayuran sesuai rekomendasi minimum sebanyak 3 porsi sehari. ${ }^{18}$

Berdasarkan Riskesdas tahun 2007 dan 2013, prevalensi penduduk Indonesia yang kurang mengkonsumsi sayuran dan buah masing - masing sebesar 93,6\% dan 93,5\%.19,20 Berdasarkan penelitian yang dilakukan di TK Budi Mulya Semarang menunjukkan bahwa sebagian besar sampel mengkonsumsi sayuran dalam kategori kurang yaitu $85,7 \%$ dengan rata - rata konsumsi $70,4 \mathrm{~g} /$ hari. ${ }^{21}$ Hasil tersebut hampir sama dengan penelitian yang dilakukan di TK Supriyadi Semarang tahun 2010 dimana sebanyak 93,6\% sampel mengkonsumsi sayuran dalam kategori kurang dengan rata - rata konsumsi 73,5 g/hari. ${ }^{22}$

Konsumsi sayuran yang rendah pada anak anak dipengaruhi oleh preferensi makanan. ${ }^{23}$ Preferensi makanan merupakan ukuran kesukaan atau ketidaksukaan terhadap suatu jenis makanan. ${ }^{24}$ Mencicipi sejumlah kecil makanan tanpa menekankan pada berapa banyak yang dimakan adalah strategi untuk menunjukkan bahwa seseorang menyukai makanan. ${ }^{23}$ Preferensi terhadap sayuran dipengaruhi oleh faktor positif (rasa manis) maupun faktor negatif (rasa pahit). ${ }^{25}$ Penerimaan terhadap rasa manis dari sayuran akan mendorong anak untuk menyukai sayuran tersebut dan mengkonsumsinya. Sebaliknya, rasa pahit dari sayuran menimbulkan penerimaan yang rendah untuk makanan ini.
Faktor penghambat penerimaan terhadap sayuran disebabkan ketidaksukaan anak pada sifat sensorik yang melekat pada sayuran terutama dari segi rasa. ${ }^{26}$ Rasa pahit yang mendominasi pada sayuran akan mengkondisikan anak untuk tidak menyukai rasa dari sayuran yang menyebabkan penerimaan dan konsumsi yang terhadap sayuran rendah. ${ }^{25}$ Rasa pahit yang terdapat dalam sayuran disebabkan adanya senyawa yang terkandung di dalam sayuran tersebut seperti fenol, flavonoid, isoflavon, terpene, dan glukosinolat. ${ }^{27}$ Sebagai contoh, glukosinolat neoglukobrassicin dan sinigrin diidentifikasi sebagai faktor yang menyebabkan rasa pahit pada kembang kol. ${ }^{28}$

Rasa pahit pada sayuran dianggap sebagai penanda adanya zat beracun yang terdapat didalamnya sehingga mereka menghindari dan menolak sayuran tersebut sebagai upaya perlindungan diri dari keracunan makanan..$^{29,30}$ Preferensi bawaan terhadap rasa manis juga membuat individu cenderung menolak rasa pahit dari makanan. ${ }^{9}$ Hal ini menunjukkan bahwa penerimaan buah lebih tinggi dibandingkan dengan penerimaan sayuran meskipun konsumsi keduanya masih sama - sama belum memadai. Selain itu, adanya perilaku neophobia yaitu perilaku dimana anak cenderung takut dan menolak makanan baru. ${ }^{31}$ Kecenderungan anak menolak makanan baru untuk memastikan hubungan antara rasa dan efek makan makanan tersebut. ${ }^{29}$ Sayuran yang tidak biasa tersedia di rumah atau di lingkungan sekitar anak menjadi hal yang asing sehingga mereka enggan untuk menerimanya.

Perilaku neophobia terhadap makanan ini bukan tidak suka permanen terhadap makanan baru, tetapi tidak suka sementara yang dapat diubah melalui pengalaman atau kebiasaan makan. ${ }^{32}$ Neophobia terhadap makanan merupakan bagian dari perkembangan normal anak. ${ }^{33}$ Makanan yang paling sering ditolak oleh anak - anak dengan tingkat neophobia tinggi adalah makanan yang berpotensi paling berbahaya karena racun yang hadir dalam banyak makanan nabati. Rasa asam dan pahit pada sayuran ini dimungkinkan menandakan adanya racun didalamnya sehingga ada keraguan pada anak untuk mengkonsumsinya. ${ }^{6,29,34}$ Pengalaman awal dan penerimaan terhadap makanan sangat penting karena anak akan menyukai dan mengkonsumsi makanan tersebut. Oleh karena itu, berbagai strategi perlu dilakukan untuk meningkatkan penerimaan sayuran pada anak agar konsumsinya mencapai jumlah yang direkomendasikan.

Salah satu strategi yang dilakukan untuk meningkatkan penerimaan sayuran pada anak 
adalah dengan hidden vegetable. Strategi ini berupa penambahan puree (bubur) sayuran ke dalam makanan. ${ }^{35,36}$ Puree sayuran merupakan hasil penghancuran sayuran dengan cara menumbuk, menggiling, atau memotong sayuran sampai teksturnya halus seperti bubur. ${ }^{37}$ Penambahan puree sayuran ke dalam berbagai macam makanan manis dan gurih memiliki kesempatan lebih besar untuk meningkatkan penerimaan sayuran daripada penyajian sayuran dalam bentuk cincang atau utuh. ${ }^{36} \mathrm{Hal}$ ini karena penambahan puree sayuran ke dalam makanan sedikit berpengaruh terhadap rasa makanan sehingga rasa dari hidangan aslinya masih bisa dipertahankan.

Berdasarkan penelitian yang telah dilakukan pada 40 anak prasekolah di Bennett Family Center and Child Development Laboratory of Pennsylvania State University menunjukkan bahwa $>70 \%$ dari mereka menyukai hidangan yang diberi tambahan puree sayuran. Selain itu, penambahan puree sayuran sebanyak $32 \mathrm{~g}$ ke dalam $100 \mathrm{~g}$ hidangan ini juga dapat meningkatkan konsumsi sayuran sebesar $73 \%$ pada anak prasekolah. ${ }^{35}$ Penelitian lain yang dilakukan pada orang dewasa di Amerika Serikat juga menunjukkan hasil yang sama bahwa penambahan puree sayuran ke dalam makanan ini meningkatkan konsumsi sayuran pada orang dewasa sebesar $80 \% .{ }^{36}$ Penelitian serupa belum ada di Indonesia. TK PGRI 21 Karangasem Kota Semarang berada di pusat kota dan dekat dengan pasar tradisional. Hal ini menunjukkan bahwa ketersediaan dan akses terhadap sayuran tergolong mudah, namun sebagian besar siswa tidak menyukai sayuran. Oleh karena itu, peneliti tertarik melakukan penelitian dengan judul "Intervensi Hidden Vegetable terhadap Penerimaan Sayuran pada Anak Prasekolah di TK PGRI 21 Karangasem, Kota Semarang". Penelitian ini bertujuan untuk mengetahui adanya perbedaan penerimaan sayuran anak prasekolah.

\section{METODE}

Penelitian ini termasuk dalam ruang lingkup keilmuan gizi masyarakat. Penelitian ini merupakan penelitian praexperimental design dengan rancangan static group comparison. Populasi dalam penelitian ini adalah siswa TK PGRI 21 Karangasem, kota Semarang. Besar sampel yang digunakan dalam penelitian ini sebanyak 10 orang untuk masing - masing kelompok baik kelompok kontrol maupun kelompok perlakuan. Teknik pengambilan sampel dalam penelitian ini menggunakan purposive sampling. Teknik pengambilan sampel ini didasarkan pada kriteria inklusi dan kriteria eksklusi.
Kriteria inklusi dalam penelitian ini adalah siswa berusia $3-5$ tahun yang orang tuanya bersedia menandatangani informed consent dan tidak memiliki riwayat alergi makanan. Kriteria eksklusi dalam penelitian ini adalah tidak patuh terhadap intervensi yang diberikan, mengundurkan diri pada saat penelitian berlangsung, dan tidak hadir atau sakit pada saat penelitian berlangsung.

Variabel terikat (dependent) dalam penelitian adalah penerimaan sayuran. Variabel bebas (independent) adalah pemberian $50 \mathrm{~g}$ hidangan dengan $16 \mathrm{~g}$ sayuran rebus pada kelompok kontrol dan pemberian $50 \mathrm{~g}$ hidangan dengan penambahan $16 \mathrm{~g}$ puree sayuran pada kelompok perlakuan. Sayuran rebus yang diberikan untuk kelompok kontrol dibumbui dengan garam. Pemberian hidangan diberikan selama 3 hari berturut - turut dengan jenis hidangan dan sayuran yang berbeda untuk setiap harinya baik untuk kelompok kontrol maupun kelompok perlakuan. Hidangan untuk kelompok kontrol berupa bakso ayam dan sawi hijau rebus untuk hari pertama, nugget ayam dan wortel rebus untuk hari kedua, serta perkedel kentang dan brokoli rebus untuk hari ketiga. Hidangan untuk kelompok perlakuan berupa bakso sawi hijau untuk hari pertama, nugget ayam wortel untuk hari kedua, dan perkedel brokoli untuk hari ketiga. Jenis hidangan dan jenis sayuran yang digunakan dalam penelitian ini dipilih berdasarkan studi pendahuluan yang dilakukan sebelumnya. Pelaksanaan penelitian telah mendapatkan persetujuan dari Komisi Etik Fakultas Kedokteran Universitas Diponegoro Semarang melalui terbitnya Ethical Clearance.

Pengolahan dan analisis data menggunakan program komputer. Analisis univariat digunakan untuk mengetahui karakteristik subjek penelitian. Analisis bivariat digunakan untuk mengetahui perbedaan penerimaan sayuran antara kelompok kontrol dan kelompok perlakuan diuji dengan menggunakan uji Chi-Square dengan syarat sel yang mempunyai nilai expected count kurang dari 5, maksimal 20\% dari jumlah sel. Jika syarat uji Chi-Square tidak terpenuhi, maka dipakai uji alternatifnya yaitu uji Fisher's Exact Test.

\section{HASIL PENILITIAN Karakteristik Subjek}

Sebanyak 20 siswa di TK PGRI 21 Karangasem menjadi subjek dalam penelitian ini. Dua puluh subjek ini dibagi menjadi 2 kelompok yaitu kelompok kontrol dan kelompok perlakuan dengan jumlah untuk masing - masing kelompok sebanyak 10 orang yang terdiri dari laki - laki dan perempuan. Usia subjek pada kelompok dalam 
penelitian ini berada pada rentang $4-5$ tahun. Pendidikan orang tua (ibu) subjek berada pada rentang SMP sampai dengan Perguruan Tinggi dan mayoritas adalah SMA yaitu sebanyak 12 orang $(60 \%)$. Orang tua (ibu) yang bekerja sebanyak 9 orang $(45 \%)$ dan yang tidak bekerja sebanyak 11 orang $(55 \%)$.

\section{Perbedaan Penerimaan Sayuran pada Anak Prasekolah}

Perbedaan penerimaan sayuran pada kelompok kontrol dan kelompok perlakuan disajikan dalam tabel 1.

Tabel 1. Perbedaan penerimaan sayuran pada kelompok kontrol dan kelompok perlakuan

\begin{tabular}{|c|c|c|c|c|c|}
\hline \multirow{3}{*}{ Tingkat penerimaan sayuran } & \multicolumn{4}{|c|}{ Kelompok } & \multirow{3}{*}{$P$} \\
\hline & \multicolumn{2}{|c|}{ Kontrol $(n=10)$} & \multicolumn{2}{|c|}{ Perlakuan $(n=10)$} & \\
\hline & $\mathrm{n}$ & $\%$ & $\mathrm{n}$ & $\%$ & \\
\hline \multicolumn{6}{|l|}{ Tingkat penerimaan sawi hijau } \\
\hline Tidak Suka & 9 & 90,0 & 1 & 10,0 & $0,000^{\mathrm{a}}$ \\
\hline Suka & 1 & 10,0 & 9 & 90,0 & \\
\hline \multicolumn{6}{|l|}{ Tingkat penerimaan wortel } \\
\hline Tidak Suka & 6 & 60,0 & 0 & 0 & $0,011^{\mathrm{b}}$ \\
\hline Suka & 4 & 40,0 & 10 & 100,0 & \\
\hline \multicolumn{6}{|l|}{ Tingkat penerimaan brokoli } \\
\hline Tidak Suka & 7 & 70,0 & 1 & 10,0 & $0,020^{\mathrm{b}}$ \\
\hline Suka & 3 & 30,0 & 9 & 90,0 & \\
\hline
\end{tabular}

${ }^{a}$ Uji Chi-Square

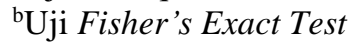

Tabel 1 menunjukkan hasil tingkat penerimaan untuk masing - masing jenis sayuran baik pada kelompok kontrol maupun kelompok perlakuan. Tingkat penerimaan sawi hijau diuji dengan menggunakan uji Chi-Square didapatkan nilai $\mathrm{p}=0,000$. Karena nilai $\mathrm{p}<0,05$ maka dapat disimpulkan bahwa terdapat perbedaan penerimaan sawi hijau pada kelompok kontrol dan kelompok perlakuan. Tingkat penerimaan wortel dan brokoli diuji dengan menggunakan uji Fisher's Exact Test didapatkan nilai $\mathrm{p}$ masing - masing yaitu 0,011 dan 0,020 . Karena keduanya memiliki nilai $\mathrm{p}<0,05$ maka dapat disimpulkan bahwa terdapat perbedaan penerimaan wortel dan brokoli pada kelompok kontrol dan kelompok perlakuan. Pada kelompok kontrol jumlah subjek yang menyukai sawi hijau sebanyak 1 orang (10\%), wortel 4 orang (40\%), dan brokoli 3 orang (30\%); sedangkan pada kelompok perlakuan jumlah subjek yang menyukai sawi hijau sebanyak 9 orang $(90 \%)$, wortel 10 orang $(100 \%)$, dan brokoli 9 orang (90\%).

\section{PEMBAHASAN}

Hidden vegetable merupakan strategi berupa penambahan puree (bubur) sayuran ke dalam makanan. ${ }^{32,35}$ Pada penelitian ini subjek pada kelompok kontrol diberi $50 \mathrm{~g}$ hidangan dengan $16 \mathrm{~g}$ sayuran rebus, sedangkan pada kelompok perlakuan diberi hidangan sebanyak $50 \mathrm{~g}$ dengan penambahan puree sayuran sebanyak $16 \mathrm{~g}$. Besar porsi yang diberikan dalam penelitian ini adalah setengah porsi dari penelitian sebelumnya yaitu $100 \mathrm{~g}$ hidangan dengan penambahan puree sayuran sebanyak $32 \mathrm{~g} .{ }^{35}$ Pemberian porsi hidangan dalam jumlah kecil ini dimaksudkan untuk mengurangi adanya sisa makanan dan mengurangi kepadatan energi. ${ }^{38}$

Hidden vegetable merupakan strategi untuk meningkatkan penerimaan sayuran yang terlepas dari kesukaan anak pada jenis sayuran tertentu, sehingga strategi ini dapat digunakan untuk meningkatkan penerimaan berbagai jenis sayuran termasuk sayuran yang secara umum tidak disukai anak. ${ }^{39}$ Hal ini dikarenakan penambahan puree sayuran ke dalam makanan tetap mempertahankan rasa dan tekstur dari hidangan aslinya. Jenis sayuran yang digunakan dalam penelitian ini adalah sawi hijau, wortel, dan brokoli yang dipilih berdasarkan dari ketersediaan dan akses terhadap sayuran tersebut. Ketersediaan dan akses yang mudah terhadap sayuran dimungkinkan memiliki hubungan positif dengan penerimaan dan konsumsi sayuran pada anak..$^{40}$ Makanan yang sering tersedia di lingkungan mereka dan mudah diakses ini akan membuat anak menyukai dan sering mengkonsumsi makanan tersebut. Jenis hidangan yang digunakan adalah bakso ayam, nugget ayam, dan perkedel kentang didasarkan pada kesukaan anak pada makanan tersebut yang didapatkan dari studi pendahuluan sebelumnya. Jenis hidangan yang digunakan dalam penelitian ini merupakan hidangan yang biasa tersedia di lingkungan sekitar anak bahkan disukai oleh mereka, sehingga anak mau dengan baik untuk menerima dan mengkonsumsinya. Penelitian ini dilakukan selama 
3 hari berturut - turut dengan jenis hidangan dan sayuran yang berbeda - beda.

Perbedaan penerimaan sayuran pada anak prasekolah dalam penelitian ini ditunjukkan dengan melihat konsumsi hidangan yang diberikan. Mencicipi sejumlah kecil makanan tanpa menekankan pada berapa banyak yang dimakan adalah strategi untuk menunjukkan bahwa seseorang menyukai makanan tersebut. ${ }^{23}$ Anak yang menyukai sayuran ini mau mengkonsumsi sedikit maupun mengkonsumsi hidangan tanpa ada sisa, sedangkan yang tidak menyukai sayuran ditunjukkan dengan mengkonsumsi hidangan kemudian dikeluarkan kembali atau tidak mau mengkonsumsinya sama sekali. Subjek pada kelompok perlakuan sebagian besar menyukai hidangan yang diberikan dibandingkan pada kelompok kontrol. Hal ini dikarenakan penambahan hidden vegetable dalam hidangan pada kelompok perlakuan ini dapat mempertahankan rasa asli hidangan aslinya dan jenis hidangan yang diberikan merupakan hidangan yang disukai oleh anak sehingga penerimaannya lebih baik dibandingkan pada kelompok kontrol. Pada kelompok kontrol menunjukkan tidak ada penerimaan yang baik, meskipun pemberian sayuran dalam kelompok ini diberi bumbu (garam) dan disajikan bersama dengan makanan pendamping yang disukai anak.

Penambahan puree sayuran sebanyak $16 \mathrm{~g}$ ke dalam $50 \mathrm{~g}$ hidangan akan menyumbang sebanyak $10,67 \%$ dari jumlah rekomendasi konsumsi sayuran harian anak yaitu $150 \mathrm{~g} / \mathrm{hari}$ apabila hidangan dikonsumsi hingga habis..$^{11}$ Meskipun dalam jumlah yang kecil, namun ini bisa ditingkatkan sesuai dengan jumlah dan frekuensi hidangan yang diberikan. Hasil ini sesuai dengan studi sebelumnya yang menyatakan bahwa penambahan puree sayuran ke dalam hidangan anak dapat meningkatkan konsumsi sayuran sebanyak $73 \%$ pada anak prasekolah dan $80 \%$ pada orang dewasa. ${ }^{35,36}$ Namun, ada perbedaan dimana pada penelitian ini hanya meningkatkan konsumsi sayuran pada anak dalam jumlah yang lebih kecil dibandingkan penelitian sebelumnya. Hal ini dikarenakan jumlah pemberian hidangan yang ditambah dengan puree sayuran hanya setengah porsi dari jumlah hidangan pada penelitian sebelumnya dan diberikan untuk satu kali waktu makan bukan keseluruhan waktu makan dalam sehari.

Berdasarkan hasil uji yang telah dilakukan, ada perbedaan penerimaan sawi hijau, wortel, dan brokoli antara kelompok kontrol dan perlakuan dengan penerimaan sayuran lebih tinggi pada kelompok perlakuan. Hal ini sesuai dengan studi sebelumnya bahwa penambahan puree sayuran ke dalam berbagai macam makanan kesukaan anak merupakan strategi efektif untuk meningkatkan penerimaan sayuran dibandingkan penyajian sayuran dalam bentuk cincang maupun utuh. ${ }^{36}$ Alasan tersebut dikaitkan dengan adanya rasa pahit yang melekat pada sayuran. Rasa pahit dalam sayuran diduga berakibat pada ketidaksukaan terhadap sayuran sehingga penerimaan dan konsumsi sayuran tersebut menjadi rendah. ${ }^{25}$ Selain itu, penolakan rasa pahit yang terdapat dalam sayuran ini dimungkinkan adanya kecenderungan pada rasa manis dan anggapan bahwa rasa pahit pada sayuran itu menandakan adanya zat beracun yang terkandung di dalamnya sehingga mereka berupaya menghindari atau menolak makanan tersebut. ${ }^{9,29,30}$

Tingkat penerimaan sawi hijau pada kelompok kontrol sebanyak $10 \%$, sedangkan pada kelompok perlakuan sebanyak $90 \%$. Tingkat penerimaan wortel pada kelompok kontrol sebanyak $40 \%$ sedangkan pada kelompok perlakuan $100 \%$. Tingkat penerimaan brokoli pada kelompok kontrol sebanyak $30 \%$ sedangkan pada kelompok perlakuan sebanyak $90 \%$. Hasil penelitian ini sesuai dengan penelitian sebelumnya yang dilakukan pada anak prasekolah di Bennett Family Center and Child Development Laboratory of Pennsylvania State University yang menunjukkan bahwa $>70 \%$ dari mereka menyukai hidangan yang diberi tambahan puree sayuran. ${ }^{35}$ Selain itu, penelitian ini juga menunjukkan bahwa dari 3 jenis sayuran yang digunakan, wortel memiliki tingkat penerimaan yang lebih tinggi dibandingkan sawi hijau dan brokoli baik pada kelompok kontrol maupun kelompok perlakuan. Hal ini dimungkinkan karena proses pembuatan puree sedikit mengurangi rasa pahit dari sayuran dan penambahan puree sayuran ke dalam makanan tetap mempertahankan rasa dari hidangan aslinya. Selain itu, adanya rasa manis dalam sayuran meskipun dalam jumlah yang sedikit sudah cukup untuk mengkondisikan preferensi untuk rasa sayuran itu dan mendorong untuk menerima dan mengkonsumsinya terutama pada penyajian sayuran dalam bentuk utuh. ${ }^{41}$ Rasa manis dalam sayuran ini terkait dengan adanya kandungan sukrosa didalamnya. ${ }^{25,41}$ Dominasi rasa pahit pada sawi hijau dan brokoli ini yang menyebabkan sebagian besar subjek pada kelompok kontrol tidak menyukai sayuran tersebut meskipun dihidangkan bersama dengan hidangan lainnya. Kandungan glucosinolate yang terdapat dalam brokoli ini yang menyebabkan rasa pahit pada sayuran tersebut. ${ }^{41}$

Pada kelompok perlakuan sebagian besar subjek menyukai hidangan yang ditambah dengan 
puree sawi hijau dan puree brokoli meskipun terdapat masing - masing 1 subjek yang tidak menyukai hidangan tersebut karena mereka merasakan bahwa rasa pahit dari sawi dan brokoli masih sedikit terasa pada hidangan yang disajikan. Satu subjek yang tidak menyukai hidangan ini merupakan subjek yang berbeda. Hal ini yang menyebabkan tingkat penerimaan sawi hijau dan brokoli lebih rendah dibandingkan tingkat penerimaan wortel meskipun ketiganya menunjukkan bahwa ada perbedaan antara kelompok kontrol dan perlakuan. Kelompok perlakuan yang menggunakan hidden vegetable tingkat penerimaan sayuran lebih tinggi dibandingkan dengan kelompok kontrol.

Meskipun hidden vegetable menjadi salah satu strategi efektif yang dapat meningkatkan penerimaan dan konsumsi sayuran pada anak, bukan berarti strategi ini tidak memiliki kelemahan. Kelemahan strategi ini adalah adanya penurunan atau kerusakan zat gizi yang terkandung didalam sayuran, seperti vitamin $\mathrm{C}$, vitamin $\mathrm{B}$, vitamin $\mathrm{A}$, vitamin $\mathrm{E}$, mineral, dan serat. Vitamin $\mathrm{C}$ merupakan vitamin larut air dan sensitif terhadap panas, cahaya, dan oksigen sehingga rentan terhadap proses pengolahan. ${ }^{42}$ Penurunan kandungan vitamin $\mathrm{C}$ dapat menurun sebanyak $15-55 \%$ tergantung pada cara pengolahannya. Vitamin B khususnya vitamin B1 mudah larut dalam air sehingga mencuci sayuran tidak perlu dilakukan berkali - kali atau penggunaan air rebusan tidak boleh terlalu banyak agar tidak banyak vitamin B1 yang hilang. ${ }^{42}$ Vitamin A dan E merupakan vitamin larut lemak yang sensitif terhadap panas, cahaya, oksigen, dan $\mathrm{pH}$. Mineral dan serat relatif tidak sensitif terhadap pengolahan termal sehingga kandungan mineral dan serat dalam sayuran segar maupun dalam bentuk olahan tetap sama. ${ }^{42}$ Oleh karena itu, perlu diperhatikan proses pengolahan sayuran agar kandungan zat gizi yang terdapat didalamnya tidak rusak atau banyak yang hilang.

Penambahan puree sayuran ke dalam makanan adalah teknik sederhana yang dapat diterapkan di pusat penitipan anak, sekolah, rumah sakit, dan rumah. ${ }^{35} \mathrm{Hal}$ ini diasumsikan bahwa proses pembuatan puree sayuran relatif mudah dan memerlukan waktu yang relatif singkat sehingga mudah untuk diaplikasikan. Selain itu, puree sayuran juga sudah ada di pasaran sehingga ini akan lebih praktis terutama bagi ibu yang bekerja karena dengan waktu menyiapkan makanan untuk keluarga yang relatif singkat atau terbatas masih bisa menerapkan metode ini. Namun, strategi ini perlu dikombinasikan dengan strategi lainnya seperti paparan berulang dan menyediakan porsi besar untuk jenis sayuran yang disukai anak agar memiliki dampak yang signifikan untuk meningkatkan penerimaan dan konsumsi sayuran sesuai jumlah yang direkomendasikan dan bisa menjadi pola makan yang menetap sampai usia dewasa. ${ }^{43,44}$

\section{SIMPULAN}

Terdapat perbedaan penerimaan sawi hijau, wortel, dan brokoli antara kelompok kontrol dan kelompok perlakuan.

\section{DAFTAR PUSTAKA}

1. Ramos M, Stein LM. Development children's eating behavior. J. pediatr. (Rio J.). 2000; 76 (Supl.3): S229S237.

2. Byrne E \& Nitzke S. Preschool children's acceptance of a novel vegetable following exposure to messages in a storybook. Journal of Nutrition Education \& Behavior. 2002;34(4):211.

3. Steinmetz KA, Potter JD. Vegetables, fruit, and cancer prevention: a review. J Am Diet Assoc 1996;96:1027-39.

4. Hu FB. Plant-based foods and prevention of cardiovascular disease: an overview. Am J Clin Nutr 2003;78(suppl):544S-51S.

5. Riboli E, Norat T. Epidemiologic evidence of the protective effect of fruit and vegetables on cancer risk. Am J Clin Nutr 2003;78(suppl):559S-69S.

6. World Cancer Research Fund/American Institute for Cancer Research. Food, nutrition, physical activity, and the prevention of cancer: a global perspective. Washington, DC: AICR, 2007.

7. Dauchet L, Amouyel P, Hercberg S, Dallongeville J. Fruit and vegetable consumption and risk of coronary heart disease: a meta-analysis of cohort studies. J Nutr 2006;136:2588-93.

8. He FJ, Nowson CA, MacGregor GA. Fruit and vegetable consumption and stroke: meta-analysis of cohort studies. Lancet 2006;367:320-6.

9. Cooke L, Wardle J, Gibson EL. Relationship between parental report of food neophobia and everyday food consumption in 2-6 year-old children. Appetite. 2003;41(2):205-6.

10. Pomerleau J, McKee M, Lobstein T, Knai C. The burden of disease attributable to nutrition in Europe. Public Health Nutr 2003;6:453-61.

11. United States Departement of Agriculture. 2010. MyPlate food groups [cited on 2014, September 28].

12. Evans CEL, Christian MS, Cleghorn CL, Greenwood DC, Cade JE. Systematic review and meta-analysis of scholl-based interventions to improve daily fruit and vegetable intake in children aged 5 to $12 \mathrm{y}$. Am J Clin Nutr 2012;96:889-901.

13. Guenther PM, Dodd KW, Reedy J, Krebs-Smith SM. Most Americans eat much less than recommended amounts of fruits and vegetables. J Am Diet Assoc 2006;106:1371-9. 
14. Krebs-Smith SM, Cook A, Subar AF, Cleveland L, Friday J, Kahle LL. Fruit and vegetable intakes of children and adolescents in the United States. Arch Pediatr Adolesc Med 1996;150:81-6.

15. Fox MK, Pac S, Devaney B, Jankowski L. Feeding infants and toddlers study: what foods are infants and toddlers eating? J Am Diet Assoc 2004;104:s22-30.

16. Mennella JA, Ziegler P, Briefel R, Novak T. Feeding Infants and Toddlers Study: the types of foods fed to Hispanic infants and toddlers. J Am Diet Assoc 2006;106:S96-106.

17. Dennison B, Rockwell HL, Baker SL. Fruit and vegetable intake in young children. Journal of the American College of Nutrition. 1998;17(4):371-78.

18. U.S. Department of Agriculture, Agricultural Research Service. Food and Nutrient Intakes by Children 1994-96, 1998.

19. Soendoro T. Riskesdas Nasional 2007. Badan Penelitian dan Pengembangan Kesehatan [serial online] 2008 [cited on 2014, May 04].

20. Trihono. Riskesdas Nasional 2013. Badan Penelitian dan Pengembangan Kesehatan [serial online] 2013 [cited on 2014, May 05].

21. Rosidi A, Sulistyowati E. Peran pendidikan dan pekerjaan ibu dalam konsumsi sayur anak prasekolah. Semarang; 2012.

22. Putriana MI. Konsumsi sayur dan buah pada anak prasekolah terkait dengan pengetahuan gizi dan sikap ibu. Semarang: Fakultas Kedokteran Universitas Diponegoro; 2010.

23. Suhardjo. Berbagai Cara Pendidikan Gizi. Ed.1. Jakarta: PT. Bumi Aksara; 2003. p.25-6.

24. Wardle J, Herrera M-L, Cooke L, Gibson EL. Modifying children's food preferences: the effects of exposure and reward on acceptance of an unfamiliar vegetable. Europe Journal of Clinical Nutrition (2003) 57, 341-348.

25. Dinehart ME, Hayes JE, Bartoshuk LM, Lanier SL, Duffy VB. Bitter taste markers explain variability in vegetable sweetness, bitterness, and intake. Physiol Behav. 2006;87(2):304-313.

26. Engel E, Baty C, Issanchou S, Martin N. Acceptance and preference for cooked cauliflower: relationship with consumer sensitivity and product composition. 5th pangborn sensory science symposium. Boston, Mass' Elsevier, 2003 abstract.

27. Drewnowski A, Gomez-Carneros C. Bitter taste, phytonutrients, and the consumer: a review. Am J Clin Nutr 2000;72(6):1424- 35.

28. Engel E, Baty C, LeCorre D, Souchon I, Martin N. Flavor-active compounds potentially implicated in cooked cauliflower acceptance. J Agric Food Chem 2002;50(22):6459-67.

29. Cooke L, Wardle J, Gibson EL. Relationship between parental report of food neophobia and everyday food consumption in 2-6 year-old children. Appetite. 2003;41(2):205-6.

30. Bergström K, Brembeck H, Jonsson L, et al. 2012. Children and Taste: Guiding Foodservice. Journal of Foodservice Business Research. 15(1): 84-100.
31. Anzman-Frasca S, Savage JS, Marini ME, Fisher JO, Birch LL. Repeated exposure and associative conditioning promote preschool children's liking of vegetables. Appetite 2012; 58(2): 543-53.

32. Gardner BM. Increasing preschool children's acceptance of vegetables [thesis]. Bowling Green State University; 2007.

33. Bellows L, Cole K, Anderson Gabel J. Gem no. 409. Family fun with new foods: a parent component to the Food Friends social marketing campaign. Journal of Nutrition Education \& Behavior. 2006; 38(2):123.

34. Addessi E, Galloway AT, Visalberghi E, Birch LL. Specific social influences on the acceptance of novel foods in 2-5 year-old children. Appetite. 2005;45(3):264-71.

35. Spill MK, Birch LL, Roe LS, Rolls BJ. Hiding vegetables to reduce energy density: an effective strategy to increase children's vegetable intake and reduce energy intake. Am J Clin Nutr 2011;94:73541.

36. Blatt AD, Roe LS, Rolls BJ. Hidden vegetables: an effective strategy to reduce energy intake and increase vegetable intake in adults. Am J Clin Nutr 2011;93:756-63.

37. Dahl, W. J. Pureed foods for swallowing problems. University of Florida; 2011.

38. Savage JS, Fisher JO, Marini M, Birch LL. Serving smaller age-appropriate entre' e portions to children aged 3-5 y increases fruit and vegetable intake and reduces energy density and energy intake at lunch. Am J Clin Nutr 2012;95:335-41.

39. Spill MK, Birch LL, Roe LS, Rolls BJ. Eating vegetables first: the use of portion size to increase vegetable intake in preschool children. Am J Clin Nutr 2010;91:1237-43.

40. Anzman-Frasca S, Savage JS, Marini ME, Fisher JO, Birch LL. Repeated exposure and associative conditioning promote preschool children's liking of vegetables. Appetite 2012; 58(2): 543-53.

41. Schonhof I, Krumbein A, Bruckner B. Genotypic effects on glucosinolates and sensory properties of broccoli and cauliflower. Nahrung 2004; 48(1):2533.

42. Barrett D.M. Maximizing the Nutritional Value of Fruits and Vegetables. Review of literature on nutritional value of produce compares fresh, frozen, and canned products and indicates areas for further research. 2007.

43. O'Connell, Meghan, L., Henderson, Kathryn,E., Luedicke., Joerg, Schwartz et al. Repeated Exposure in a Natural Setting: A Preschool Intervention to Increase Vegetable Consumption. 2012. J Acad Nutr Diet. 2012 Feb;112(2):230-4.

44. Spill MK, Birch LL, Roe LS, Rolls BJ. Eating vegetables first: the use of portion size to increase vegetable intake in preschool children. Am J Clin Nutr 2010;91:1237-43. 